\title{
Braverman, subjetividade e função de direção na produção do valor
}

\author{
Braverman, subjectivity and function of direction in the value production
}

Elcemir Paço Cunha ${ }^{1}$

Trabalho e capital monopolista, de Harry Braverman (1920-1976), desde 1974 segue sendo um texto de referência para o debate marxista (e não marxista) sobre o processo de trabalho e as formas complexas por meio das quais o domínio do capital se desenvolve e se reproduz.

As palavras de Paul M. Sweezy (1977, p. 11) à época são válidas para demarcar o livro em questão, mesmo passados 40 anos de sua primeira publicação: "[a] função desta obra é muito mais suscitar do que responder a questões". Esse é o espírito da obra que cortou tantas décadas, tendo por ponto de arranque um singular encontro entre a investigação dos textos fundamentais do marxismo, da experiência pessoal como trabalhador e militante socialista, além do senso de realidade que transborda das linhas que armam o texto. Marxista de inclinações trotskistas, deveu muito às análises de Paul Baran e Paul Sweezy em Capital monopolista, contribuindo indubitavelmente ao avançar no estudo sobre as consequências que certos modos de transformação também tecnológica trouxeram ao processo de trabalho e à classe trabalhadora.

O livro de Braverman é importante por uma série de questões além daquelas já convencionais quando esse é o assunto. Com frequência, é exaltado por revigorar criticamente uma sociologia do trabalho estacionada nas estatísticas e por lançar as bases de uma Teoria do Processo de Trabalho cuja crítica possibilitou o desenvolvimento dos chamados Estudos Críticos da Gestão (Critical Management Studies). A despeito dessa derivação, a chamada Teoria do Processo de Trabalho congrega muitos pesquisadores em todo o mundo, gera publicações e pauta eventos internacionais de grande expressão.

Entretanto, Braverman também é memorável pelo nexo que buscou desenvolver entre a produção do maisvalor e a progressiva tendência à proletarização da classe trabalhadora, seja do trabalho qualificado ou sem qualificação, seja do gerente ou do operário, no interior e externamente à produção industrial. Esse desenvolvimento serve ao combate à tese lançada com frequência, inclusive em época recente no Brasil, de um dito "aburguesamento" de muitas esferas da atividade humana. Braverman mostra, ao contrário, a tendência mais forte à decaída dos diferentes processos de trabalho, dentro e fora da indústria - incluindo os escritórios -, sob os mesmos efeitos que assolam os trabalhadores tradicionalmente ligados à produção direta das mercadorias físicas. Sob esse ângulo, a precarização do trabalho, por exemplo, não seria uma exclusividade da esfera diretamente econômica, nem do trabalho manual no interior dela. É o que se pode constatar (guardadas as diferenças) em diversas esferas do trabalho, dos canaviais brasileiros às universidades norte-americanas. A ilusão à qual se prendeu a sociologia acadêmica (e sua terminologia, white-collars, blue-collars etc.) ao tempo de Braverman e à qual também se agarra hoje, desesperadamente, o discurso político, é aquela que sustenta um crescimento da "classe média". A argumentação de Braverman mostra, entre muitas outras coisas, que o fenômeno não se deve à "vontade política" e, em especial, não é a

Artigo submetido em 29 de setembro de 2014 e aceito para publicação em 12 de novembro de 2014.

DOI: http://dx.doi.org/10.1590/1679-395138853

1 Doutor em Administração pela UFMG; Professor Adjunto do Departamento de Ciências Administrativas; Professor do Programa de Pós-Graduação em Direito e do Programa de Pós-graduação em Serviço Social da Universidade Federal de Juiz de Fora. Endereço: Universidade Federal de Juiz de Fora, Campus Universitário, s/no, Bairro Martelos, CEP: 36036-900, Juiz de Fora - MG, Brasil. Email: paco.cunha@ufjf.edu.br 
criação ou desenvolvimento do "meio-termo", mas o crescimento progressivo da massa de trabalho improdutivo (que não cria valor, isto é, trabalho nas esferas comercial, financeira e de escritório, este último também dentro da própria indústria) sob o comando do capital, se comparado aos trabalhos diretamente produtivos (ligados ao capital produtivo) que adicionam novo valor ${ }^{2}$.

Por esses pontos, Braverman permanece importante para a discussão sobre a lógica do valor, questão retirada de cena sempre que possível em nome de abstrações que esfumaçam as contradições reais. É importante, ainda, como trincheira diante do avanço do irracionalismo e suas variadas manifestações, que pregam a indeterminação da realidade e um subjetivismo solipsista à beira do niilismo derrotista, que negam a contradição no movimento próprio das coisas e mistificam o existente, sobretudo em uma forma de sociabilidade arqueada pelo poder do capital e seu impulso insaciável de autovalorização. Todavia, a própria efetividade cobra seu preço do irracionalismo. O movimento dessa realidade concreta cria as condições e tendências de sua própria transformação, cuja realização, contudo, não se dá sem a atuação efetiva dos homens ao converterem, por meio da práxis histórica, as tendências em efeitos postos conscientemente. " $\mathrm{O}$ irracionalismo é a forma que assume [...] a tendência a esquivar a solução dialética de problemas dialéticos", como sugeriu Lukács (1958, p. 193). É por esses e outros motivos que Braverman precisa ser lido e debatido, inclusive para explicitar suas deficiências, com o rigor que o autor merece.

No sentido de contribuir para o debate de pontos importantes do livro em questão, seguem abaixo ao menos dois que se mostram centrais, mas sem qualquer intenção de esgotar a discussão. Ao final, são indicados os artigos profundamente instigantes, tanto no conjunto como de modo individual, que configuram esta edição especial inestimável.

Os dois pontos importantes giram em torno, de um lado, do problema da subjetividade, a partir do qual se ergueram rios de páginas hostis a Braverman. É preciso esclarecer alguns pontos a respeito. De outro lado, tratamos do caráter produtivo e improdutivo da função de direção, isto é, do trabalho do administrador na produção do valor como trabalho de explorar exercitado por fração do trabalho explorado - uma dimensão que Braverman mesmo não pôde desenvolver suficientemente.

\section{Subjetividade}

Uma das maiores polêmicas certamente gira em torno do problema da subjetividade. Em parte, Braverman pode ser responsabilizado por uma dificuldade que cobra seu preço, mesmo depois de quarenta anos. Entretanto, apenas em parte.

A certa altura da introdução de Trabalho e capital monopolista, nosso autor explicou que não intentava cuidar "do estudo da moderna classe trabalhadora no nível de sua consciência, organização ou atividades. Este livro [disse ele] trata da classe trabalhadora como classe em si mesma e não como classe para si mesma" (BRAVERMAN, 1977, p. 33-34, grifo do autor). Não há lugar para longas digressões que lidem com uma das grandes questões do marxismo, isto é, a diferenciação entre classe em si e classe para si. Digamos, brevemente, que a segunda refere-se ao estágio em que a classe já tem esclarecida sua missão histórica, reconhece-se como classe e empreende ato social e político com o intuito de transformar a realidade social e superar as relações de classe. A primeira, por sua vez, refere-se à existência da classe em suas condições objetivas, mas ainda incapaz (por diferentes razões) de converter essa condição em movimento histórico. Ao se concentrar na classe em si, Braverman tem em mente "um quadro da classe trabalhadora tal qual existe, com a forma dada à população trabalhadora pelo processo de acumulação primitiva do capital" (BRAVERMAN, 1977, p. 34). O autor americano estava bastante esclarecido dos problemas dessa alternativa analítica. Como ele mesmo explica:

${ }^{2}$ Essas categorias (valor, trabalho produtivo e improdutivo) serão discutidas mais adiante em certo detalhe. 
Esta limitação autoimposta ao conteúdo objetivo de classe e a omissão do sujeito, receio que comprometerá irremediavelmente este estudo aos olhos daqueles que flutuam na corrente convencional da ciência social. Para eles, por longo hábito e insistente teoria, a classe não existe realmente fora de suas manifestações subjetivas. Classe, status, "estratificação", e até mesmo o assunto da moda [hobby horse] dos últimos anos, que foi tomado a Marx sem a mínima compreensão de seu significado, "alienação" - tudo isto são para a ciência social burguesa artefatos de consciência que só podem ser estudados na medida em que se manifestam nas mentes da população em foco. Pelo menos duas gerações de sociologia acadêmica elevaram este enfoque de tal modo à categoria de dogma que só raramente se sente necessidade de substantivá-lo (BRAVERMAN, 1977 p. 34; 1998, p. $19)^{3}$.

Como uma espécie de antecipação das críticas que viriam, Braverman sugere uma das marcas mais decisivas do marxismo, a de que a realidade opera de maneira independente da consciência dos homens que vivem essa mesma realidade - o que não significa que a consciência não desempenharia qualquer papel. Talvez nosso autor não tenha dedicado palavras suficientes para uma explicação mais acabada dessa questão, deixando ao menos aludido que as condições sociais da existência de uma classe seguem existindo de modo independente da elaboração consciente dos indivíduos que compõem essa classe. Nosso autor explicitou, na antecipação da crítica, que para "aqueles que flutuam na corrente convencional da ciência social", a classe, o status, a "alienação" etc. são incompreensíveis senão como "artefatos de consciência", coisas que só existem nas mentes dos grupos que compõem o objeto da pesquisa sociológica. Embora não tenha desenvolvido suficientemente seu argumento, o autor americano é coerente com seus fundamentos e almeja avaliar as condições de classe e não os movimentos históricos da classe para si. É o que lemos, muitas páginas depois, ao afirmar que "a existência de uma classe trabalhadora como tal não depende das diversas formas concretas de trabalho que lhe cabe desempenhar, mas, isto sim, de sua forma social" (BRAVERMAN, 1977, p. 347). E completou, parágrafos depois: "a variedade de determinadas formas de trabalho pode influir na consciência, coesão ou atividade econômica e política da classe trabalhadora, mas não afeta a existência dela como classe" (BRAVERMAN, 1977, p. 347). Era disso que se tratava para o autor nova-iorquino em 1974.

Braverman não fazia ideia de que seus críticos iriam muito mais longe do que pôde antecipar. Como comentou O'Doherty (2009, p. 5-6), "Braverman é tipicamente lido e associado a uma forma monocausal e teleológica da historiografia marxista à qual falta nuance histórica, sutileza dialética e sofisticação teórica". As críticas de outra qualidade vieram, primeiro, a partir de uma inclinação gramsciana pelas mãos de Michael Burawoy e, depois, por leituras daí derivadas, mas em um corte mais diverso e, por vezes, avesso ao marxismo. Contudo, mesmo essas críticas guardam limitações. Vejamos.

Burawoy (1983) não se restringe a Braverman; apresenta um Marx não dialético, como portador de uma descrição do regime fabril restrito ao momento coercitivo. Supõe-se que Marx teria visto apenas esse momento da produção historicamente determinada. Por diferença, no contemporâneo, em que a dependência do trabalho em relação ao capital é alegadamente menor, o método não pode ser outro senão a produção ideológica. Essa posição de Burawoy em relação à produção é a mesma que muitos gramscianos sustentam em relação ao Estado, posição segundo a qual em Marx vigeria uma "concepção restrita" do Estado (COUTINHO, 1996; 2012), estacionado no momento coercitivo. Existem provas, porém, que colocam em dúvida este último entendimento (PAÇO CUNHA, 2014), tendo também em mente que o modo coercitivo do Estado é "impossível como a forma política normal da sociedade, insuportável mesmo para a massa das classes médias" (MARX, 2011a, p. 171). Existem provas, ainda, no que tange à produção (cf. PAÇO CUNHA, 2010, p. 310-326), uma vez que Marx demonstrou que no lugar do chicote surge o manual de penalidades: um tipo de regulação social do processo de trabalho nesse momento do desenvolvimento da produção capitalista que dista de uma mera coerção. Dito de outra forma, Marx já apreendia em seu tempo a

\footnotetext{
${ }^{3}$ As passagens que aparecem com dupla referência constituem tradução de nossa autoria derivada de cotejamento com a tradução para o português da edição de 1977.
} 
transição da coerção mais direta e violenta durante o processo de gênese do capitalismo às formas mais sutis de exercício do "poder de direção" [Regierungsgewalt] (MARX, 1985, p. 484), na medida em que, inclusive, "no evolver da produção capitalista desenvolve-se uma classe de trabalhadores que, por educação, tradição e hábito, reconhece as exigências desse modo de produção como leis naturais e evidentes por si mesmas" (MARX, 2013, p. 808). Qual é a participação das relações imediatas na produção nesse processo de criação do hábito, por exemplo? Não está aí explícito que o momento da produção não encerra apenas coerção virulenta?

Com isso, é possível avaliar que as críticas ao Braverman também ecoam sobre Marx. Se as críticas não procedem em relação a Marx, o que dizer sobre as que recaem diretamente sobre o autor americano? Vejamos:

[...] os problemas básicos: Braverman assume que os aspectos "objetivo" e "subjetivo" do processo de trabalho possam ser separados e analisados independentemente um do outro. [...] seus críticos argumentam que "uma compreensão do controle do capital [...] não pode ser localizado sem a devida atenção aos componentes 'subjetivos' do trabalho" (BURAWOY, 1985, p. 24) (WILLMOTT, 1990, p. 337).

É preciso esclarecer que Braverman não parece ter "assumido que os aspectos objetivos e subjetivos do processo de trabalho podem ser separados e analisados independentemente um do outro", como lemos acima. Vimos antes que nosso autor pretendia tratar da classe em si, isto é, como ela surge nas condições da produção do capital independente da elaboração consciente que a classe faça dessas condições. A determinação bastante objetiva de que a realidade possui movimento próprio, independente da consciência, converte-se, para os críticos de Braverman (e também para os de Marx ${ }^{4}$ ) em uma separação entre objetividade e subjetividade no processo de trabalho. Aliás, Braverman seria o último a discordar de que uma "compreensão do controle do capital não pode ser alcançada sem a atenção devida aos componentes subjetivos do trabalho", como sugerem seus críticos acima. E o que o autor americano tem a dizer diretamente a respeito?

O capítulo seis, denominado "A habituação do trabalhador ao modo capitalista de produção", é (por acaso?) repleto de indicações sobre esses processos mediados pela subjetividade, muito próximas, aliás, daquela consideração marxiana de antes a respeito da formação da classe trabalhadora. Existem muitos outros pontos no texto que também trazem essa questão para o primeiro plano. Entretanto, fiquemos apenas com o capítulo seis. O ponto de partida é bastante ilustrativo: "[...] a habituação dos trabalhadores ao modo capitalista de produção deve ser renovada a cada geração" (BRAVERMAN, 1977, p. 124). E completou:

[...] a necessidade de ajustar o trabalhador ao trabalho em sua forma capitalista, de superar a resistência natural intensificada pela tecnologia mutável e alternante, relações sociais antagônicas e a sucessão de gerações, não termina com a "organização científica do trabalho", mas se torna um aspecto permanente da sociedade capitalista (BRAVERMAN, 1977, p. 124).

Como é possível afirmar que a habituação socialmente posta não é resultado histórico mediado pela subjetividade?

Braverman estende consideravelmente a análise sobre o desenvolvimento das pesquisas de inclinações psicológicas e, depois, sociológicas. A crise de 1929 fez com que a fábrica aparecesse

${ }^{4}$ Para uma discussão sobre a relação entre objetividade e subjetividade em Marx e resposta aos problemas postos por autores dos chamados Estudos Críticos da Gestão e outros mais, ver Bicalho (2014). 
[...] subitamente não como um sistema de organização burocrática formal no modelo weberiano, não como um sistema de relações de grupo informal, como na interpretação de Mayo e seus seguidores, mas antes como um sistema de força, de antagonismos de classe (BRAVERMAN, 1977, p. 129).

Nosso autor considerava que tais pesquisas não foram tão aptas no desenvolvimento de medidas imediatamente práticas que atendessem às necessidades reais da produção se comparadas ao taylorismo e, por isso, tiveram pouca influência sobre a habituação dos trabalhadores à produção do capital. Talvez o autor americano tenha subestimado tais influências, mas sua consideração serve de base para lançar uma questão decisiva: "Se a adaptação do trabalhador ao modo capitalista de produção deve pouco aos esforços dos manipuladores práticos e ideológicos, como de fato ela se realiza?" (BRAVERMAN, 1977, p. 129). Braverman reconhece na "histórica econômica e política do mundo capitalista" o papel principal no "processo de ajustamento, dos conflitos e revoltas que o acompanham" (BRAVERMAN, 1977, p. 129) - e como poderiam encaminhar conflitos e revoltas sem a mediação da subjetividade? Ao destacar o fordismo, o autor nova-iorquino pretende mostrar o caráter preponderante - não mecânico, não único, não unidirecional - das "condições e forças socioeconômicas" se comparadas com a "manipulação ou bajulação" (BRAVERMAN, 1977, p. 129-30) promovida pelos estudos psicológicos e sociológicos.

O ponto central para Braverman é que, com o desenvolvimento do fordismo e com o espraiamento dessa lógica da produção para virtualmente todas as demais esferas econômicas, ilustra-se a

[...] regra de que a classe trabalhadora está progressivamente submetida ao modo capitalista de produção, e às formas sucessivas que ele assume, apenas à medida que o modo capitalista de produção conquista e destrói todas as demais formas de organização do trabalho, e com elas, todas as alternativas para a população trabalhadora (BRAVERMAN, 1977, p. 132, grifo do autor).

Em outros termos, trata-se de tornar objetivamente "todos os outros meios de vida impossíveis" (BRAVERMAN, 1977, p. 133).

Essa constatação, entretanto, não é índice de desconsideração dos aspectos subjetivos no processo de trabalho, como seus críticos sugeriram (a despeito do fato de haver alguma perda na excessiva concentração nesses padrões produtivos, como taylorismo, fordismo). Como o próprio Braverman (1977, p. 133) explica:

Se as mínimas manipulações dos departamentos de pessoal, a Psicologia e Sociologia da indústria não desempenharam papel mais importante na habituação do trabalhador ao trabalho, consequentemente isto não significa que o "ajustamento" do trabalhador está isento de elementos manipulativos. Pelo contrário, como em todo funcionamento do sistema capitalista, a manipulação vem em primeiro lugar e a coerção é mantida na reserva - exceto que esta manipulação é o produto de forças econômicas poderosas, políticas de emprego e barganha, e a atuação e evolução íntimas do próprio sistema capitalista, e não primacialmente dos hábeis esquemas de peritos em relações trabalhistas.

Seja pela consideração do papel principal das condições e forças socioeconômicas, seja pela indicação do caráter progressivamente manipulativo do capitalismo com vistas ao "ajustamento", isto é, à constituição do hábito, ambos os movimentos (complementares, diga-se de passagem) são impensáveis sem a mediação da subjetividade "dentro e fora dos muros" que cercam a produção. É um devaneio considerar o contrário. E, como é possível ver, Braverman (assim como Marx) não recusou, como não poderia mesmo recusar, a mediação da subjetividade. Para além da constatação de que nosso autor não desenvolveu razoavelmente tal problema de grande magnitude, poderíamos questionar se a história real autoriza uma desconsideração tão radical dos problemas da consciência de classe. Poderíamos, ainda, perguntar se Braverman não teria subestimado demasiadamente os efeitos dos estudos manipulativos na produção do valor e fora dela, em 
esferas de domínio do capital comercial, financeiro, ou mesmo para além do complexo econômico imediato. Outra coisa, porém, é afirmar que Braverman teria desconsiderado por inteiro o momento subjetivo no processo de trabalho, que teria cindido tal momento de seu necessário complemento, o momento objetivo. Parece que, desse ângulo, aquela derivação (os chamados Estudos Críticos da Gestão), engendrada tendo por base essa consideração sobre Braverman, possui um problema de fundamento. Não se deve questionar Braverman por meio de falsos problemas.

Ao final dessa consideração sobre a subjetividade, é possível ver as mazelas que esses mal-entendidos históricos provocam e que transcendem os limites de Trabalho e capital monopolista. Tenhamos em mente, por exemplo, a tão frequentemente evocada distinção entre mecanismos de controle objetivo e subjetivo. Segundo se conta, o capitalismo de estágio anterior se fundou no controle objetivo do trabalho e, no posterior, no controle subjetivo. Com frequência, também se ligam os pontos, associando taylorismo a controle objetivo e os padrões posteriores a controle subjetivo. Ora, é de supor que os trabalhadores na virada do século XIX para o XX vendiam-se sem suas cabeças! Basta uma leitura dos Princípios de administração científica, de Taylor, para apreciar o momento subjetivo; "Schmidt" que o diga (cf. TAYLOR, 1953, p. 4447). Qualquer explicação que obstrua as conexões entre a objetividade e a subjetividade no movimento concreto-prático não é uma explicação. Não é tão fácil ignorar, por exemplo, que "a apropriação da vontade alheia é o pressuposto da relação de dominação" (MARX, 2011b, p. 411). Nem mesmo nas formas mais coercitivamente explícitas de dominação a subjetividade está ausente. Ela é momento ineliminável do movimento prático dos homens. O capítulo seis de Braverman prova que ele tinha isso muito bem claro, a despeito das leituras de seus críticos ou dos limites intrínsecos no tratamento do tema ${ }^{5}$.

\section{Função de direção na produção do valor}

Braverman também abre outras questões importantes, largamente deixadas em segundo plano pela elaboração mais desenvolvida na grande área dos chamados Estudos Organizacionais. Trata-se da lógica do valor e seus condicionantes sobre a vida social, inclusive sobre a função de direção na produção econômica, isto é, o trabalho de administrar.

Uma das coisas mais interessantes é o destaque que distingue a análise de Braverman daquelas mais abstratas como, por exemplo, a demarcação do trabalho do administrador como tomada de decisões, resolução de problemas ou, ainda, como a realização das etapas de um ciclo administrativo, muito bem conhecido por todos que passaram pelos cursos de Administração. O autor americano, munido de seu profundo sentido de realidade, destaca que "o problema tal como se apresenta aos homens que administram a indústria, o comércio e as finanças é muito diferente do problema como aparece nos mundos acadêmicos ou jornalísticos" (BRAVERMAN, 1977, p. 41). E completou:

[...] o administrador está habituado a conduzir processos de trabalho num ambiente [setting] de antagonismo social e, de fato, jamais o conheceu de outro modo. Os gerentes de empresa não têm nem esperança nem expectativa de alterar essa circunstância por um único golpe; ao contrário, eles estão ocupados com a melhoria apenas quando interfere no funcionamento ordenado de suas fábricas, escritórios, armazéns e lojas. Para o gerente corporativo isso é um problema nos custos e nos controles, não na "humanização do trabalho". Exige sua atenção porque manifesta-se no absenteísmo, na rotatividade de pessoal [turnover] e nos níveis de produtividade que não se conformam com seus cálculos e expectativas. As soluções que aceitarão são apenas aquelas que promovem melhorias nos

${ }^{5}$ Sem mencionar o capítulo 1, sobre "Trabalho e força de trabalho", que revela o momento subjetivo no trabalho humano como algo "consciente e proposital" (BRAVERMAN, 1977, p. 50) e, logo, o lugar decisivo da subjetividade em todo e qualquer processo de trabalho humano. 
custos do trabalho e nas posições competitivas nos mercados doméstico e mundial (BRAVERMAN, 1977, p. 41; 1998, p. 25).

Demarcar o trabalho do administrador que opera na dimensão econômica como atividade que se resolve no interior do antagonismo social tem a vantagem de explicitar de maneira concreta, não abstrata, os reais imperativos que nascem das próprias relações sociais de produção capitalistas. Desse modo se vai à raiz do problema e, para lembrar um ilustre florentino a respeito de outra ordem de questões, à verità effecttuale della cosa. Braverman abre, assim como outros autores importantes que remontam a Marx, a possibilidade e a necessidade de considerar tal atividade de direção a partir da lógica do valor.

Considerando que seria impossível explicitar sequer as nuances centrais dessa lógica, não seria um grande desserviço determinar o valor como tempo de trabalho socialmente necessário, sob condições históricas particulares, à produção das mercadorias, sendo elas próprias forma de valor. Escreveu nosso autor que todos os produtos do trabalho na produção capitalista "carregam as marcas invisíveis da propriedade" e que, para além de "sua forma física, há sua forma social como valor" (BRAVERMAN, 1977, p. 256, grifo do autor). Esse ponto de partida de Braverman, de uma "teoria do valor-trabalho" (BRAVERMAN, 1977, p. 54), ilumina o propósito da produção de mercadorias, isto é, "um processo para a expansão do capital" (BRAVERMAN, 1977, p. 55-56; 1998, p. 36). Como a produção capitalista não é mero processo de trabalho na feitura de coisas úteis, já que também é processo de criação de valor, de valorização, o movimento dessa unidade respeita a trama posta pelo valor de troca que domina seu pressuposto objetivo, o valor de uso. Essa marca central implica, para Braverman $(1977$, p. 56; 1998, p. 37), compreender a "maneira pela qual o processo de trabalho é dominado e modulado pela acumulação do capital", isto é, compreender como o valor domina as necessidades reais dos homens. Braverman $(1977$, p. 217) apreende a relação entre o "movimento do valor e o movimento do trabalho", inspirado na exposição de Marx sobre a "lei geral da acumulação capitalista", porém - é importante dizer - conforme desenvolvida por Baran e Sweezy em Capital monopolista. Esses condicionantes da produção do valor podem ser apreendidos, seguindo Braverman, nas esferas imediatamente econômicas e para além delas. O progressivo movimento do capital, escreveu Braverman (1977, p. 218):

[...] reorganizou totalmente a sociedade, e ao criar a nova distribuição do trabalho criou a vida social amplamente diferente daquela de apenas setenta ou oitenta anos passados. E esta incansável e insaciável atividade do capital continua a transformar a vida social quase que diariamente diante de nossos olhos, sem cuidar em que ao assim fazer está criando uma situação na qual a vida social torna-se cada vez mais impossível.

Descontando o tom apocalíptico ao final da passagem, o ponto central é que "o excedente do trabalho distribuído em novas formas de produção ou não produção" incorreu no fato de que "a estrutura ocupacional e portanto a classe trabalhadora foi transformada" (BRAVERMAN, 1977, p. 218). Com palavras mais incisivas, explicou Braverman que a força de trabalho, como "a parte viva do capital, sua estrutura ocupacional, modos de trabalho e distribuição pelas atividades da sociedade [...] são determinados pelo processo em curso de acumulação do capital". Essa força, completou, "é captada, liberada, arremessada pelas diversas partes da maquinaria social e expelida por outras, não de acordo com sua própria vontade ou atividade própria, mas de acordo com os movimentos do capital" (BRAVERMAN, 1977, p. 320). Ou, ainda, "uma sociedade que se baseia na forma do valor submete mais e mais de sua população trabalhadora às complexas ramificações das exigências da propriedade do valor" (BRAVERMAN, 1977, p. 258).

Se existe nexo entre o movimento do valor e o movimento do trabalho, a atividade de direção exercida frequentemente por administradores (atividade de direção) na produção do valor (ou mesmo fora dela) também deve receber condicionamentos complexos. Isso é procedente porque, por um lado, o "motivo que impulsiona e a finalidade que determina o processo de produção capitalista é a maior autovalorização possível do capital, isto é, a maior produção possível de mais-valor e, portanto, a máxima exploração possível da força de trabalho pelo capitalista” (MARX, 2013, p. 406). Por outro lado: 
O comando do capitalista não é apenas uma função específica, proveniente da natureza do processo social de trabalho e, portanto, peculiar a esse processo, mas, ao mesmo tempo, uma função de exploração de um processo social de trabalho, sendo, por isso, determinada pelo antagonismo inevitável entre o explorador e a matéria-prima de sua exploração (MARX, 2013, p. 406).

Agora ele [o capitalista individual ou coletivo, depois do crescimento do seu capital] transfere a função de supervisão direta e contínua dos trabalhadores individuais e dos grupos de trabalhadores a uma espécie particular de assalariados [...] que exerçam o comando durante o processo de trabalho em nome do capital (MARX, 2013, p. 407).

Ao mesmo tempo em que a atividade de direção realizada pelo administrador é efetivada da ótica do capital, esses homens e mulheres não são outra coisa senão trabalhadores assalariados. Braverman desenvolve esse ponto de partida considerando as alterações provocadas na fase monopolista do capitalismo. É verdade que desenvolve mais o primeiro lado da equação (o motivo e a finalidade do processo), deixando apenas algumas indicações sobre o caráter assalariado do administrador - o que tentaremos desenvolver adiante -, porque tendeu a obscurecer o problema pela total inclusão dessa atividade na categoria do trabalho improdutivo. Não obstante, trata-se de apreender o considerável "crescimento na escala de operações gerenciais" (BRAVERMAN, 1977, p. 222). Disso resulta que:

A função especial de administração é exercida não mais por um único gerente, nem mesmo por uma equipe de gerentes, mas por uma organização de trabalhadores sob o controle de gerentes, assistentes de gerentes, supervisores etc. Assim, as relações de compra e venda da força de trabalho, e, em consequência, de trabalho alienado, tornou-se parte do aparelho gerencial em si mesmo (BRAVERMAN, 1977, p. 228, grifo do autor).

As análises de Braverman são originais porque buscam, como dissemos antes, abarcar os condicionantes gerais da lógica do valor inclusive em esferas não imediatamente produtivas, não industriais, por assim dizer. Ele se ocupa em larga medida dos efeitos sobre os trabalhadores dos escritórios, inclusive com a "gerência do escritório" como um "produto do período monopolista do capitalismo" (BRAVERMAN, 1977, p. 259). Um dos elementos importantes dessa análise é a distinção entre trabalho produtivo e improdutivo, questão à qual Braverman dedicou um capítulo.

Em termos sintéticos, o autor americano aceita, e com razão, a posição de Marx de que "o trabalho produtivo no capitalismo" é "aquele que produz valor de mercadoria [commodity value], e, por conseguinte, maisvalor ${ }^{6}$ para o capital. Isto exclui todo o trabalho que não é trocado por capital" (BRAVERMAN, 1977, p. $348 ; 1998$, p. 285). Com o desenvolvimento do capitalismo, várias outras modalidades do trabalho caem na categoria do trabalhador produtivo. Vê-se que "a transformação do trabalho improdutivo em trabalho produtivo que é, para os fins do capitalista de extrair mais-valor, o próprio processo da criação da sociedade capitalista" (BRAVERMAN, 1977, p. 249; 1998, p. 286). Onde quer que se desenvolva o capitalismo, mais difícil é a existência de trabalhos improdutivos fora do domínio do capital. Isso significa que nem todo trabalho que cai sob seu domínio converte-se necessariamente em trabalho produtivo, porque isso depende do momento da produção total em que tal trabalho se realiza. Por isso, Braverman (1977, p. 351, grifo do autor) escreveu que "enquanto o trabalho improdutivo declinou fora do alcance do capital, aumentou dentro do seu âmbito". Isso o leva à importante distinção entre o que ele denomina "funções adicionais", além da produção imediata do valor: realização do valor e apropriação do valor. Enquanto a primeira se liga à circulação das mercadorias no mercado, a segunda expressa a "luta de capitais em concorrência pelo

\footnotetext{
${ }^{6}$ Braverman utiliza a expressão "surplus value", que é correspondente a "mais-valia" ou, melhor ainda, a "mais-valor", conforme a nova edição de $O$ capital, publicada pela editora Boitempo em 2013. A tradução de Trabalho e capital monopolista optou por "valor excedente" (com exceção do título do capítulo 11, onde se lê "mais-valia e trabalho excedente"), mas isso retira o traço decisivo do processo de valorização que o termo consagrado reserva.
} 
valor, e sua transferência e redistribuição de acordo com exigências individuais, especulações e os 'serviços' do capital sob a forma de crédito etc." (BRAVERMAN, 1977, p. 351). Essas funções, explica Braverman (1977, p. 350), mobilizam "enormes volumes de trabalho" que, embora "necessário para o modo capitalista de produção, é em si improdutivo, visto que não amplia o valor ou o mais-valor". Nosso autor, aqui, busca seguir Marx (2013, p. 238), para quem "a circulação ou a troca de mercadorias não cria valor nenhum", lembrando, porém, que o "capital não pode ter origem na circulação, tampouco pode não ter origem na circulação. Ele tem de ter origem nela e, ao mesmo tempo, não ter origem nela" (MARX, 2013, p. 240), isto é, o processo total da produção do capital tem na circulação das mercadorias ponto de passagem necessário, mas esse momento do movimento total não adiciona novo valor.

O trabalho realizado, pois, no escritório é trabalho improdutivo, uma vez que não cria novo valor e está mais ligado à realização e à apropriação do valor já criado. A despeito disso, "o mercado de trabalho para as duas principais variedades de trabalhadores, escritório e fábrica, começa a perder algumas de suas distinções de estratificação social, instrução, família e coisas semelhantes" (BRAVERMAN, 1977, p. 298). Trata-se, e este é o ponto, da "criação de um vasto proletariado sob forma nova" (BRAVERMAN, 1977, p. 299-300).

A atividade do administrador se confirma tanto na produção imediata como naquilo que Braverman chamou de realização e apropriação que, não obstante, ocorrem tanto distantes do processo de produção das mercadorias como no interior da própria produção imediata. Como apreender esse conjunto, produtiva ou improdutivamente? E os efeitos, também são muito semelhantes? Braverman pouco desenvolve, diretamente, esses dois pontos, porém, de modo comparativo, confere ênfase ao segundo. É esse desenvolvimento, entretanto, que o permite colocar as questões importantes. Com efeito, Braverman (1977, p. 352-353) explicou que:

Nas primitivas empresas capitalistas o trabalho improdutivo empregado em pequenas quantidades era, de modo geral, um estrato privilegiado, intimamente associado com o empregador e detentor de favores especiais. Os que trabalhavam com ele na realização de vendas, contabilidade, funções especulativas e manipulativas representavam para ele sócios na guarda e expansão de seu capital enquanto capital, distintamente daqueles na produção, que representavam seu capital apenas em sua forma temporária como trabalho. [...]. Aqueles que ajudavam o capitalista na circulação de seu capital, na realização do seu lucro, e na administração do seu trabalho, obtinham privilégios, segurança e status na função exercida, e assim, ser um trabalhador improdutivo era em si uma felicidade que contrastava com a desgraça do trabalhador na produção.

Braverman informa diretamente que as atividades típicas de escritório (vendas, contabilidade, especulação) surgem como trabalho improdutivo. Em meio a essas atividades, o autor sugere, ainda, as atividades manipulativas as quais, como vimos antes no tratamento da questão da subjetividade, expressam o ato administrativo muito ligado à direção da força de trabalho. Sob esse ponto de vista, o trabalho do administrador, mesmo aquele ligado à produção imediata, também seria trabalho improdutivo? Aguardemos momento oportuno para retomar essa questão. O importante é destacar que muitas mudanças ocorreram no modo de produção capitalista de tal maneira que "o processo de trabalho produtivo tornou-se, mais do que nunca, um processo coletivo" (BRAVERMAN, 1977, p. 353) e o resultado do processo (o conjunto das mercadorias) não pode ser atribuído a qualquer trabalhador singular. Entretanto, Braverman (1977, p. 353) destaca com maior ênfase que "do lado do trabalho improdutivo foi criada uma massa que partilha da sujeição e opressão que caracteriza as vidas dos trabalhadores produtivos". Assim, o processo de proletarização assume escala universal para o modo de produção capitalista:

As funções improdutivas, tendo evoluído de ocupações especiais e privilegiadas intimamente associadas com o capital nas divisões da atividade empresarial ou mesmo nas "indústrias" capitalistas distintas e completas em si mesmas, produziram agora seus exércitos de assalariados cujas condições são em geral semelhantes às daqueles exércitos de trabalho organizado na produção (BRAVERMAN, 1977, p. 353). 
Nessas funções improdutivas, como vimos, estão incluídas as atividades de realização e apropriação. Tudo indica que, para Braverman, a atividade do administrador, em seu bojo, concentra-se nessas funções improdutivas. Mesmo o exercício das funções manipulativas na produção imediata determina tal atividade como trabalho improdutivo, embora Braverman, como dito antes, não tenha desenvolvido suficientemente esse aspecto importante.

Isso se explica pelo fato de que nosso autor estava concentrado em explicitar os efeitos da lógica do valor sobre os trabalhadores produtivos e, inclusive, sobre os trabalhadores de escritório, circunscritos sob o domínio do capital comercial (realização) e financeiro (apropriação). Muito embora restem diferenças na forma concreta desses trabalhos comparados ao trabalho produtivo direto no processo de valorização - que implica o grau de qualificação, níveis salariais etc. -, o ponto que se destaca é que cada vez mais o trabalho realizado no escritório é progressivamente "igualado às formas simples do assim chamado trabalho manual de colarinho azul" (BRAVERMAN, 1977, p. 276; 1998, p. 225), isto é, não são mais procedentes as distinções de fundamento entre o trabalho manual e o trabalho de escritório porque este tendencialmente é reduzido cada vez mais às formas simples de trabalho. Trata-se, como antes, não da identificação de uma atribuição social típica da classe média, mas da proletarização dessas funções desempenhadas sob o domínio do capital. Dessa maneira:

O trabalho improdutivo contratado pelo capitalista para ajudá-lo na realização ou apropriação do mais-valor é, ao ver de Marx, semelhante ao trabalho produtivo em todos os sentidos, exceto um: ele não produz valor e mais-valor, e por conseguinte aumenta não como causa, mas muito pelo contrário, como consequência da expansão do mais-valor (BRAVERMAN, 1977, p. 357; 1998, p. 292).

O trabalho improdutivo do administrador nesse contexto do escritório, no interior da própria produção imediata, informou-nos Braverman, não passa ileso a esse processo de proletarização. A relação, posta pelo autor, de progressiva identificação (guardadas as diferenças na forma concreta) entre o processo de trabalho administrativo e o processo de trabalho na produção imediata do valor implica uma relação de espelhamento:

A gerência veio a ser administração, que é um processo de trabalho efetuado para fins de controle no seio da empresa, e efetuado, além do mais, como um processo de trabalho rigorosamente análogo ao processo da produção, embora ele não produza artigo algum que não seja a operação e coordenação da empresa.

Desse ponto em diante, examinar a gerência significa também examinar esse processo de trabalho, que contém as mesmas relações antagônicas contidas no processo da produção (BRAVERMAN, 1977, p. 228).

São processos análogos, porém cindidos, segundo o entendimento de Braverman. Embora demarque o espelhamento (de identidade por vezes exagerada) e o antagonismo que se manifesta, ainda, no trabalho da gerência, Braverman separa a produção do valor, de um lado, e o processo de trabalho da coordenação dessa produção, de outro. Essa é uma dificuldade que teremos de retomar adiante. Por agora, basta-nos reforçar o espelhamento posto pelo autor a partir de sua constatação dada pela proletarização, também, do trabalho gerencial:

Em todas essas atividades, o desenvolvimento do capital transformou a função operante do capitalista de uma atividade pessoal a um trabalho de uma multidão de pessoas. A função do capitalista é representar o capital e ampliá-lo. Isso é feito ou pelo controle da produção do mais-valor nas indústrias e atividades produtivas, ou pela apropriação dele de fora daquelas indústrias e atividades. O capitalista industrial, o fabricante, é um exemplo do primeiro; o banqueiro exemplifica o segundo. Essas funções gerenciais de controle e apropriação tornaram-se por si mesmas processos de trabalho. São conduzidas pelo capital do mesmo modo como ele realiza os processos de trabalho da produção: com trabalho 
assalariado comprado em larga escala no mercado de trabalho e organizado em imensas máquinas "de produção" de acordo com os mesmos princípios que governam a organização do trabalho na fábrica (BRAVERMAN, 1977, p. 255-256; 1998, p. 208).

Ao reforçar o espelhamento explicita-se o caráter assalariado dos trabalhadores que realizam essas funções gerenciais, cujo processo de trabalho é, além da realização e da apropriação, controle na produção imediata do mais-valor. Esse trabalho assalariado, porém improdutivo, que desempenha o controle, sofre dos mesmos efeitos que os trabalhadores produtivos e que os também improdutivos que se situam fora da produção imediata do valor. Ao passo que ajuda a revelar que o trabalho da administração é a representação do capital no interesse condicionante de maior valorização possível, mostra, ainda, que esse trabalho improdutivo cai na categoria de trabalho explorado, já que também constitui capital variável junto a todos os demais trabalhos assalariados aglutinados e necessários à produção do valor. Se todos esses trabalhos são amalgamados em um trabalho coletivo imprescindível à produção do valor, como seriam improdutivos de modo pleno? Essa dificuldade advém da abstração relativamente forçada que Braverman se vê obrigado a fazer para traçar o espelhamento entre o processo de produção do valor e o processo de trabalho da gerência quando, no movimento da realidade concreta, essa desconexão não existe. Vejamos isso, enfim, mais de perto.

Alguns pontos são importantes, mas não inteiramente suficientes, dados os limites das páginas.

O primeiro é que a função de direção, a administração, não se realiza tão somente no escritório. Na verdade, a função de direção assume muitas formas e manifesta-se em diferentes pontos do conjunto organizado da produção, isto é, no interior do trabalhador coletivo. O engenheiro, por exemplo, administra, desempenha a função de direção sobre o trabalho. Até mesmo alguma parte de seu trabalho poderia ser considerada administrativa, no sentido mais restrito, como trabalho burocrático. O trabalho do engenheiro não é apenas numérico e burocrático, mas, também, social, manipulativo como sugeriu Braverman. Muitos outros tipos de trabalho podem apresentar características semelhantes a essas, a depender das circunstâncias singulares em análise. Importa destacar que existe, portanto, um risco na abstração radical do processo de trabalho gerencial como algo desconectado por completo do processo da produção do valor. Há uma passagem de Marx que Braverman possivelmente não conhecia e que é muito esclarecedora a esse respeito. Nela, Marx (1988, p. 443-444; 1969, p. 65-66, grifo do autor) diz:

Com o desenvolvimento da subsunção real do trabalho sob o capital ou o modo de produção especificamente capitalista não é o trabalhador individual, mas uma capacidade de trabalho socialmente combinada que é mais e mais o executor real [wirkliche Funktionär] do processo de trabalho em sua totalidade, e já que diferentes capacidades de trabalho as quais cooperam conjuntamente para formar uma máquina produtiva total contribui de diferentes meios para o processo direto pelo qual a mercadoria, ou, mais apropriadamente aqui, o produto, é formado, com um trabalhando mais com suas mãos, outro mais com seu cérebro, como gerente, engenheiro ou técnico, etc., outro como supervisor, um terceiro diretamente como um trabalhador manual, ou ainda como mero servente, mais e mais funções da capacidade de trabalho são incluídas no imediato conceito de trabalho produtivo, diretamente explorados pelo capital e subordinados em geral ao seu processo de valorização e de produção.

Quer dizer, quanto mais se desenvolve o modo de produção capitalista mais decisivo se torna o trabalhador coletivo. Braverman capturou esse ponto, sem dúvida. O problema está em não apreender que a função de direção, ou ao menos parte considerável dela, não está fora do trabalho combinado que produz valor, como pareceu supor Braverman. E é precisamente o fato dessa função se realizar em meio às atividades produtivas na criação da mercadoria é o que a torna uma forma de trabalho produtivo. Entretanto, a distinção que Braverman realiza é útil para a constatação de que nem todo trabalho que se inclui no trabalhador coletivo é necessariamente produtivo. Basta, para isso, ter em mente o escritório em que se confirmam as funções de realização e apropriação no interior da própria produção imediata e que também requerem uma função 
particular de direção. O trabalhador coletivo, na verdade, é formado por trabalhos improdutivos e produtivos nos quais a função de direção se manifesta em distintos pontos, tanto produtiva como improdutivamente, cortando de modo considerável o amplo conjunto. Talvez seja útil, pois, fazer distinção entre a parcela da função de direção que cai na categoria do trabalho produtivo e aquela que permanece ligada à realização e à apropriação (na classificação de Braverman). Desse modo, obtemos a vantagem de avaliar que parte considerável desse trabalho gerencial é, ao mesmo tempo, trabalho assalariado e também produtivo, porque não só participa (como os trabalhadores assalariados improdutivos) do trabalho coletivo como, ainda, adiciona valor, como a passagem de Marx acima explicita. Disso resulta que não devemos abstrair por inteiro o processo de trabalho que se confirma como comando sobre o trabalho em relação ao processo global de valorização porque parte relevante do trabalho de administração é explorada, ainda, de modo produtivo nesse processo.

Essas considerações são importantes para destacar que o salário que remunera essa força de trabalho especial se dá fora da ordem dos chamados "ganhos empresariais". Desse modo, não se deve confundir o trabalho que realiza a função de direção com capital, o que faria com que perdêssemos de vista o caráter produtivo de parte do trabalho gerencial, sem mencionar seu caráter antagônico efetivo:

O trabalho de superintendência e gerência erigido como tal a partir do antagonismo, da supremacia do capital sobre o trabalho e sendo, assim, comum a todos os modos de produção baseados nas contradições de classe como o modo de produção capitalista, é conectado direta e inseparavelmente, também sob o sistema capitalista, com as funções produtivas as quais todo trabalho social combinado atribui aos indivíduos como suas tarefas especiais. Os salários de um epitropos, ou régisseur como era chamado na França feudal, são inteiramente divorciados do lucro e assumem a forma de salários para trabalho qualificado sempre que a atividade é operada sobre uma escala suficientemente ampla para garantir o pagamento de tal MANAGER, embora nossos capitalistas industriais estejam longe de "atender aos assuntos do Estado ou dedicados ao estudo da filosofia" (MARX, 1998, p. 384).

A função de direção (superintendência, gestão) no modo de produção capitalista não nasce simplesmente por efeito do trabalho combinado, mas, antes, em razão do caráter antagônico do processo. Com isso, destacamos que, independente do caráter produtivo ou improdutivo, o trabalho de homens e mulheres no desempenho da função de direção cai na categoria do trabalho explorado e sofrem efeitos semelhantes, os quais marcaram a longa história de lutas dos trabalhadores na ponta do processo de produção do valor, como bem notou Braverman.

Contudo, aqui, também se revela uma contradição importante que relativamente escapou ao autor novaiorquino. Ao passo que são trabalho explorado como componentes do trabalhador coletivo que se realiza de modo estranhado sob o domínio do capital, representam, em grande parte, o interesse do capital de maior valorização possível. É claro que o trabalho de explorar é distinto do trabalho explorado, mas os dois aspectos se manifestam em conjunto na função de direção que se realiza diretamente como trabalho produtivo no processo de valorização. Trata-se do movimento complexo do trabalho de explorar exercitado pelo trabalho explorado, uma forma diretamente contraditória de exercício da dominação pela própria classe dominada sobre ela mesma; ou, ao menos, exercida por uma fração dominante cada vez mais dominada da classe dominada.

Esta última constatação acerca do movimento complexo ajuda a trazer de volta o problema da subjetividade que abordamos antes, e também serve de encaminhamento para o final dessas curtas considerações. Ora, não geraria qualquer espanto considerar que o processo de formação do hábito na classe trabalhadora abarca, ainda, sua fração que exercita o trabalho de explorar. Não é factível, aqui, um longo desenvolvimento. Para nossos intentos, basta destacar que as variadas individualidades que desempenham as funções de direção como trabalho assalariado (produtivo ou improdutivo) foram recrutadas em maior parte na própria classe que vive do trabalho, pois, do contrário, não precisariam vender sua força de trabalho para viver. Essa fração 
teve, ainda, de ser habituada ao exercício da função, à posição social subjetivamente elaborada que daí deriva. Sua habituação, no entanto, comporta o processo de identificação com os interesses do capital; algo necessário para o exercício da própria função. A condição de pertencer de modo objetivo à classe trabalhadora não se reflete de modo ideal, isto é, como membros da classe do trabalho, mas como algo puramente externo, bastante diferente. A própria prática concreta dessa função se encarrega de criar as condições básicas que emperram o autorreconhecimento como fração da classe trabalhadora ou ao menos como fração dominante da classe dominada. Todavia, essa habituação certamente não seria completa sem a participação também da educação formal nos bancos escolares, sobretudo nos cursos universitários de administração em que a chamada profissão é considerada não só diferente, mas, ainda, apresentada como oposta ao trabalho. Essa oposição, no entanto, é tomada como não contraditória, isto é, não se revela a raiz da questão. Em suma, não se mostra que essa oposição é dada pelo caráter antagônico do processo de produção que põe parcelas da própria classe do trabalho em relação contraditória consigo mesma. Subjetivamente, essa contradição não se mostra pronta. Trata-se da contradição em movimento na qual o trabalho explorado também se realiza como trabalho de explorar; expressão desenvolvida da concorrência no interior da própria classe do trabalho.

Por fim, cabe dizer que esses pontos não têm a menor pretensão de forçar uma crítica a Braverman, mas de apresentar algum desenvolvimento possível a partir das questões que ele mesmo abriu ao longo da exposição de Trabalho e capital monopolista. E, se podemos promover algum andamento das questões, deve-se à qualidade do material que Braverman legou a pelo menos duas ou três gerações de pesquisadores inquietados com a crítica e a transformação da sociedade para além dos limites da pré-história da humanidade.

Nesse sentido, os trabalhos que compõem esta edição comemorativa aos 40 anos da publicação de Trabalho e capital monopolista também exploram diferentes questões abertas por Braverman, inclusive, elaboram análises críticas sobre diferentes pontos do texto ou até adotam uma literatura bastante diversa em relação aos pilares que o autor norte-americano sustentou.

O artigo que abre esta edição, assinado por Fabiane Santana Previtali e Cílson César Fagiani, é intitulado Organização e controle do trabalho no capitalismo contemporâneo: a relevância de Braverman. $\mathrm{O}$ texto propõe uma revisita às teses centrais do livro seminal de Braverman, buscando analisar a problemática introdução das inovações técnicas no estágio de desenvolvimento do capitalismo no século XXI. Os autores apresentam considerações que ajudam a revelar a intensificação, a flexibilização e a precarização das condições de trabalho sob a celebração contemporânea acerca da qualificação e recombinação do trabalho mental e manual.

$\mathrm{Na}$ esteira dessas questões que tocam a precarização do trabalho, o segundo artigo, de Maria Beatriz Rodrigues, intitulado Trajetórias de vida e de trabalho flexíveis: o processo de trabalho pós-Braverman, busca apresentar as alterações promovidas no capitalismo a partir da década de 1980 e, entre elas, o processo de flexibilização como parte do desenvolvimento do capitalismo em sua fase pós-fordista. Captura, a partir dos casos italiano e brasileiro, os complexos efeitos da flexibilização ainda em operação sobre as condições de vida e de trabalho, incluindo os impactos sobre o potencial de mobilização de classe dos trabalhadores.

O problema das classes sociais no capitalismo é o tema do terceiro artigo, Revisiting the issue of class structure in Labor and monopoly capital, contribuição internacional assinada por Bruno Tinel. Além da retomada dessa problemática central que corta todo o livro de Braverman, o texto aponta determinados enlaces não resolvidos pelo autor nova-iorquino a respeito da polarização de classes no desenrolar do desenvolvimento do capitalismo. Entre a polarização de classes e a variabilidade no espectro da estrutura de classes, Tinel situa as tendências e contratendências identificadas por Braverman como muito mais incertas do que pôde sugerir o próprio autor de Trabalho e capital monopolista.

O debate sobre as classes sociais nunca seria explicitado suficientemente sem a atuação do Estado capitalista. O artigo Braverman, o Estado e a "administração consensual", de Claudio Roberto Marques Gurgel, aborda os desdobramentos do papel do Estado a partir de Braverman, os quais culminam em novas formas de 
atuação estatal por mediação das crises dos anos de 1970-80 e da crise de 2008. A pesquisa bibliográfica e os dados secundários sugerem que, nessa nova fase de atuação estatal, minguam as fronteiras entre o público e o privado (administração pública consensual) e fortalece-se o processo de mercantilização de outras dimensões sociais, criando as condições para um Estado servidor plenamente compatível com o movimento gerencialista.

O quinto artigo desta edição especial é assinado por Eduardo Sartelli e Marina Kabat, constituindo outra contribuição internacional, intitulada Where did Braverman go wrong? A Marxist response to the politicist critiques. Ele traz o instigante argumento de que as deficiências da elaboração de Braverman sobre o processo de trabalho podem ser encontradas não em seus fundamentos marxistas, mas por ter renunciado propriamente a tais fundamentos, sobretudo às categorias marxistas (cooperação simples, manufatura e grande indústria) em favor de conceitos regulacionistas (taylorismo, fordismo e toyotismo). Em defesa da superioridade das categorias marxistas para a compreensão dos conflitos no processo capitalista de trabalho, o texto enfrenta criticamente as posições politicistas de David Montgomery e Michael Burawoy, dado que têm dificuldades na apreensão do momento da produção do valor como despotismo do capital e supervalorizam tal momento como se fosse aberto às iniciativas tanto do capital como dos trabalhadores. $\mathrm{O}$ ângulo central é que o processo de trabalho não é imediatamente político, como sugerem as posições politicistas. As forças decisivas são técnicas e econômicas, sobretudo pela unidade entre processo de produção e processo de valorização.

O último artigo desta edição, Experimentação do tempo e estilos de vida em contexto de trabalho imaterial, de Carmem Ligia Iochins Grisci e Jonas Cardoso, contribui com a discussão sobre as condições de trabalho nos processos contemporâneos. Sobretudo porque o texto analisa o tempo de vida e o tempo de trabalho de professores horistas do Ensino Superior privado em Porto Velho-RO. Chama a atenção no texto o fato de que, mesmo por outras vias analíticas, explicitam-se ressonâncias de uma das constatações mais fortes de Braverman: os impactos da lógica do valor também sobre trabalhadores externamente à esfera econômica imediata. O texto revela que os estilos de vida são estabelecidos a partir dos ditames do capital, isto é, é uma dada forma do processo de trabalho que condiciona a maneira como os homens vivem para além do próprio trabalho. Sobretudo, o artigo chama a atenção para o fato de que o trabalho imaterial do professor (esse proletário da educação) exige, por mediação das tecnologias informacionais, sua total disponibilidade, intensificando o trabalho e dominando todo o tempo de vida.

Na seção Opinião, os leitores encontrarão a contribuição de Claudio Katz, intitulada Discusiones sobre el control patronal, numa avaliação das teses centrais presentes em Braverman acerca de uma teoria do controle patronal, tendo em vista o desenvolvimento atual do capitalismo. Nesse sentido busca explicitar a consistência de uma teoria marxista contida em Braverman em contraste com as posições da visão neoclássica e da teoria da regulação. Destacam-se as considerações de Katz acerca dos limites da tese de Braverman sobre desqualificação absoluta do trabalho no capitalismo, bem como as considerações de que no autor nova-iorquino persiste uma perspectiva de centralidade do trabalho em contraste com o "fim do trabalho".

É importante registrar o agradecimento aos avaliadores nacionais e estrangeiros que dedicaram muito de seu tempo na elaboração da presente edição, bem como ao professor Fernando Tenório pelo incentivo e à Fabiana Braga Leal pela competente assistência.

Por fim, esperamos que os leitores do Cadernos EBAPE.BR aproveitem os textos aqui apresentados. A expectativa é suscitar debates sobre os problemas acerca do processo de trabalho contemporâneo, inclusive incentivar o surgimento de outras edições e publicações que acionem as temáticas importantes que não eliminam as contradições do mundo concreto nem a necessidade social de sua transformação efetiva. 


\section{Referências}

BICALHO, R. A. Elementos para uma análise categorial da objetividade/subjetividade em O capital (1867): um aporte teórico para os estudos organizacionais marxistas. 139f. Tese (Doutorado em Administração) - Universidade Federal de Minas Gerais, Belo Horizonte, 2014.

BRAVERMAN, H. Trabalho e capital monopolista: a degradação do trabalho no século XX. Rio de Janeiro: Zahar, 1977

Labor and monopoly capital: the degradation of work in the twentieth century. New York: Monthly Review Press, 1998.

BURAWOY, M. Between the labor process and the state: the changing face of factory regimes under advanced capitalism. American Sociological Review, v. 48, p. 587-605, 1983.

COUTINHO, C. N. Marxismo e política: a dualidade de poderes e outros ensaios. 2. ed. São Paulo: Cortez, 1996.

Gramsci: um estudo sobre seu pensamento político. 4. ed. Rio de Janeiro: Civilização Brasileira, 2012.

LUKÁCS, G. La destruction de la raison. Paris: L’Arche, 1958. v. 2.

MARX, K. Resultate des unmittelbaren Produktionsprozesses. Frankfurt: Verlag Neue Kritik, 1969.

Erstes Manuscript. In: Werke. Dietz Verlag, Berlin, Ergänzungsband, 1. Teil, 1985.

Economic manuscript. In: Collected works. London: Lawrence \& Wishart, 1988. v. 34.

Capital. In: Collected works. London: Lawrence \& Wishart, 1998. v. 37.

A guerra civil na França. São Paulo: Boitempo, 2011a.

Grundrisse. São Paulo: Boitempo, 2011b.

O capital. São Paulo: Boitempo, 2013.

O'DOHERTY, D. Revitalizing labour process theory: a prolegomenon to fatal writing. Culture and Organization, v. 15, n. 1, p. 1-19, 2009.

PAÇO CUNHA, E. Gênese, razoabilidade e formas mistificadas da relação social de produção em Marx: a organização burocrática como abstração arbitrária. 586f. Tese (Doutorado em Administração) - Centro de PósGraduação e Pesquisas em Administração, Universidade Federal de Minas Gerais, Belo Horizonte, 2010.

. Violência e formação da classe trabalhadora: limites da imputação a Marx de uma "concepção restrita" do Estado. In: COLOQUIO INTERNACIONAL TEORÍA CRÍTICA Y MARXISMO OCCIDENTAL: MARXISMO Y VIOLENCIA, 7., 2014, Buenos Aires. [s.n] Buenos Aires: [s.n], 2014. 1-8 p.

SWEEZY, P. M. Prefácio. In: BRAVERMAN, H. Trabalho e capital monopolista: a degradação do trabalho no século XX. Rio de Janeiro: Zahar, 1977. 9-12 p.

TAYLOR, F. W. Princípios de administração científica. São Paulo: Atlas, 1953.

WILLMOTT, H. Subjectivity and dialectics of praxis: opening up the core of labour process analysis. In: KNIGHTS, D.; WILLMOTT, H. (Org.). Labor process theory. London: Macmillan Press, 1990. 336-378 p. 